\title{
ENSINO DE LÍNGUA PORTUGUESA PARA A FORMAÇÃO PROFISSIONAL NA UNIVERSIDADE: AS SEQUÊNCIAS NARRATIVAS E ARGUMENTATIVAS NO GÊNERO PETIÇÃO INICIAL
}

\author{
PORTUGUESE LANGUAGE TEACHING FOR PROFESSIONAL TRAINING AT \\ UNIVERSITY: THE NARRATIVE SEQUENCE IN INITIAL PETITION GENRE
}

\author{
Ana Lúcia Tinoco Cabrak \\ Universidade Cruzeiro do Sul, São Paulo, SP, Brasil
}

\begin{abstract}
Resumo: Entre as preocupações do ensino universitário encontra-se proficiência escritora dos estudantes, especialmente no que diz respeito aos gêneros específicos das diversas áreas de atuação profissional. Relativamente à formaccão de profissionais da área do Direito, essa questão se mostra ainda mais indispensável, visto ser a língua escrita ferramenta de trabalho para o profissional desta área. 0 texto apresenta reflexões sobre 0 ensino de escrita na Universidade voltado para a formaç̃ão profissional de estudantes de Direito, focalizando o gênero Petição Inicial e 0 estatuto das sequências textuais narrativas na construção argumentativa desse gênero jurílico. Para tanto, apresenta algumas questões sobre proficiência em escrita (MOLITOR-LÜBBERT, 2010; KELLOGG E WHITEFORD, 2012; FAYOL, FOULIN, MAGGIO E LÉTÉ, 2012), traz uma breve explanação teórica das sequências narrativas (ADAM, 2011), conceitua 0 gênero Petição Inicial no escopo do Processo Civil (GRECO FILHO, 1995) e aponta algumas diretrizes a prática de escrita desse gênero na universidade.
\end{abstract}

Palavras-chave: ensino de escrita; formação profissional; proficiência escritora; gênero petição inicial; sequência textual narrativa.

\begin{abstract}
Among the concerns of university education is proficient writer of the students, especially with regard to specific genres of the various areas of professional practice. As regards training of legal practitioners, this issue proves even more indispensable, as it is written language a working tool for the professional in this area. The text presents reflections on the teaching of writing at the University focusing on vocational training law students, focusing on the Initial Application genre and status of textual narrative sequences in argumentative construction of this legal genre. It presents some questions about proficiency in writing (MOLITOR-LÜBBERT, 2010; KELLOGG AND WHITEFORD, 2012; FAYOL, FOULIN, MAGGIO AND LETE, 2012), presents a brief theoretical explanation on narrative sequences (ADAM, 2011), conceptualizes the Initial Application genre in the scope of Civil Procedure (GRECO FILHO, 1995) and points out some guidelines to writing this kind practice at the university.
\end{abstract}

Keywords: writing teaching; professional qualification; proficiency; Initial Application genre; narrative sequence.

* Professora doutora da Universidade Cruzeiro do Sul - UNICSUL, São Paulo, Brasil; altinococabral@gmail.com 
Linha D’Água (Online), São Paulo, v. 28, n. 2, p. 122-136, dez 2015

\section{Introdução}

$\mathrm{O}$ aluno ingressante na universidade tem nenhuma ou pouca familiaridade com os gêneros textuais utilizados na área profissional escolhida. Falta-lhe o conhecimento das funções sócio-comunicativas que tais gêneros cumprem e, por conseguinte, a compreensão de sua estrutura composicional. Assim também acontece com os estudantes de Direito, para cujo desempenho profissional, a língua oral e escrita, constitui um instrumento de trabalho. O papel do professor de língua materna na Universidade é torná-los proficientes em leitura e escrita de textos da área profissional escolhida. A fim de cumprir essa tarefa, defendemos o apelo aos fundamentos da Linguística Textual e da Linguística cognitiva numa perspectiva genérica. Dentre os textos da área jurídica para cuja leitura e escrita o advogado deve estar preparado, destacamos a petição inicial, gênero em que a narrativa cumpre importante função. Dito isso, o objetivo deste texto é apresentar breves reflexões sobre o ensino de escrita na universidade, voltado para a formação profissional de estudantes de Direito. Focalizamos o gênero Petição Inicial e o estatuto das sequências textuais narrativas na construção argumentativa desse gênero jurídico. A fim de cumprir o objetivo e responder a questão colocada, este trabalho divide-se em quatro partes: na primeira, discorremos brevemente sobre questões que envolvem a proficiência em escrita, fundamentando-nos em estudiosos que se voltaram para esse tema (MOLITOR-LÜBBERT, 2010; KELLOGG E WHITEFORD, 2012; FAYOL, FOULIN, MAGGIO E LÉTÉ, 2012 ); na segunda, tecemos algumas considerações sobre as sequênc ias narrativas (ADAM, 2011), procurando situar teoricamente o ponto de vista de que tratamos a narração; na terceira, apresentamos o processo civil e, dentro de seu escopo, o gênero Petição Inicial (GRECO FILHO, 1995), focalizando sua função no escopo do processo e estatuto do conflito em seu interior; por último, apontamos algumas diretrizes a prática de escrita desse gênero na universidade, destacando a estrutura sequencial narrativa e os aspectos estilísticos do gênero.

\section{A questão da proficiência em escrita na Universidade}

Antes de refletir sobre o conceito de proficiência em escrita, é importante pensar o próprio significado de "ser proficiente". Para o verbete "proficiente", o dicionário nos traz o seguinte: ser "competente e eficiente no que faz" (HOUAISS e VILLAR, 2001, p.2306). Estendendo a definição do dicionário para a área específica de nosso interesse, a produção escrita e recorrendo a Molitor-Lübbert (2010, p.132), podemos definir o escritor proficiente como aquele que tem "habilidade de comunicar-se com os outros e de articular seu pensamento pela escrita". Trata-se de uma habilidade que 
envolve muitas operações, nem todas elas de ordem linguística, de acordo com o que ensinam Coirier, Gaonac'h e Passerault (1996) e Gaonoc'h e Fayol (2003).

Embora se defina o que consiste ser proficiente em escrita, não é simples estabelecer o que permite considerar um escritor competente e eficiente. A esse respeito, vale recorrer a Kellog e Whiteford (2012, p.109), para quem "defining expertise in writing is difficult because the types of texts generated by professionals are so varied". Com base nessa afirmação, esses autores alertam que não é possível ser proficiente em escrita em geral, e defendem que "the concept of writing expertise inherently means the capacity to write texts of a particular genre" (KELLOG E WHITEFORD, 2012, P.109).

Esses autores observam que não apenas os conteúdos e conhecimento como também os discursos e os saberes retóricos variam de área para área. Isso quer dizer que o estudante, para além dos conhecimentos da área profissional para a qual se prepara, deverá apropriar-se, ao longo de seu percurso universitário, dos diferentes gêneros e discursos que circulam nessa esfera de atuação profissional, pois, como destacam mais uma vez Kellog e Whiteford (2012, p.109) "learning the appropriate genre and other literacy skills of a given profession is part and parcel of becoming an expert in the domain". As considerações desses autores indicam a importância do ensino dos gêneros específicos das áreas profissionais no ensino superior.

Evidentemente, esses autores mesmos apontam tal ressalva, há uma questão mais geral relativa à proficiência geral em escrita, que não se circunscreve apenas ao domínio de gêneros em particular, entretanto, para a prática profissional eficaz, o domínio dos gêneros específicos da área é crucial.

Com respeito à questão da proficiência em geral, que permite diferenciar um escritor experto do inexperiente, ou imaturo. A esse respeito, remetemos a Hayes e Flower (1980), que encaram a escrita como um processo de resolução de problemas envolvendo três operações cognitivas recursivas que ocorrem na mente do produtor: planejamento, escrita e revisão. O planejamento do texto tem a ver com o estabelecimento de objetivos; a escrita diz respeito à própria elaboração do tecido textual utilizando sequencias lineares de unidades linguísticas; e, finalmente, a revisão refere-se ao ao monitoramento e à edição do texto em produção. Como professores, estamos cientes de que muitas vezes, nossos alunos ignoram o planejamento e a revisão. Com efeito, os escritores imaturos, conforme observou Cabral (2013), passam da geração de ideias para a escrita. A autora observa que esse procedimento tem como consequência fazer com que o produtor se perca durante o processo de textualização.

Não podemos ignorar que a escrita constitui uma tarefa cognitiva de alta complexidade, que envolve muitas operações, nem todas elas de ordem linguística, 
conforme observam Marquesi e Cabral (2008, p. 169): "recuperar, analisar, selecionar e organizar as informações; convocar esquemas cognitivos; respeitar uma estrutura tipológica, entre outros".

Relativamente às complexidades da escrita, Fayol, Foulin, Maggio e Lété (2012, p.148) destacam a dimensão linguística, observando que a dificuldade por conta da linearização. Segundo esses autores, a linguagem verbal e o texto têm uma estrutura unidimensional, isto é, as palavras, as frases, e as diferentes partes do texto se organizam de forma linear; o conteúdo, em contrapartida, não tem uma estrutura linear, ele é multidimensional. Esses pesquisadores destacam que a complexidade se intensifica uma vez que sequencia textual deve se escolhida de acordo com o conteúdo, o receptor e de acordo com as habilidades linguísticas do produtor. Quando transferimos essas reflexões para o ensino voltado para a formação profissional de consideramos os postulados de Chuy e Rondelli (2010, p.83), "escrever um texto é construir uma unidade comunicativa destinada a ser interpretada e compreendida por um destinatário", mais uma vez, encontramos como recurso importante os gêneros e as sequências textuais para a prática de escrita.

Os gêneros que circulam na esfera jurídica têm como marca seu caráter argumentativo. A respeito da produção textual de ordem argumentativa, Fayol, Foulin, Maggio e Lété (2012) ensinam que ela exige certa maturidade do produtor, uma vez que ela demanda um conhecimento estratégico do produtor que é a (re)organização dos conceitos recuperados na memória visando ao objetivo argumentativo.

Retomando a questão dos gêneros pertinentes à área de atuação profissional para a qual se preparam os estudantes na universidade, recorremos novamente Coirier, Gaonac'h e Passerault (1996); esses autores colocam a finalidade do discurso como um parâmetro central e ressaltam a importância da articulação do discurso ao seu contexto; para eles o contexto deve ser entendido como o contexto enunciativo, o domínio de referência, as imposições da atividade em jogo.

De acordo com Coirier, Gaonac'h e Passerault (1996, p.8), quatro níveis de determinações são convocados para a compreensão e a produção de textos. Em primeiro lugar, o sistema da língua, que dizem respeito aos elementos linguísticos envolvidos tanto na construção como na recuperação da organização textual. Fazem parte desses elementos, segundo os autores, os conectores, as marcas de pontuação, a delimitação das partes do texto por parágrafos, entre outros. Em segundo lugar, o domínio de referência, ou seja, as representações mentais, os esquemas cognitivos que permitem ter acesso a propriedades do mundo físico, social e subjetivo; incluem aí também os esquemas cognitivos utilizados para analisar e estabelecer as relações do tipo causal, lógica, temporal, entre outras. Em terceiro lugar, o contexto enunciativo, e mais extensivamente, ao contexto da tarefa de produção. Em quarto 
lugar, as próprias estruturas cognitivas que participam da tarefa de escrita, o que inclui a proficiência linguística e textual, o nível de aquisição dos mecanismos da escrita e de leitura, ou sua familiaridade com modelos textuais preestabelecidos; o funcionamento da memória, e o que regula as fontes de atenção.

Essas determinações postuladas por Coirier, Gaonac'h e Passerault são de ordem geral para qualquer texto, mas elas nos permite também observar a escrita de estudantes voltados para a formação profissional, servindo tanto para verificar o seu nível de proficiência quanto para trabalhar a sua prática escrita visando à proficiência profissional, considerando inclusive as observações de Kellogg e Whiteford (2012). As quatro determinações expostas acima nos permitem defender, apoiados em Coirier, Gaonac'h e Passerault ser relevante trabalhar, desde as séries iniciais do ensino universitário, os gêneros que circulam na área profissional à qual se dirigem os estudantes, colocando-os em contato a linguagem específica da sua área profissional, permitir-lhes o acesso aos esquemas textuais próprios dela, situa-los no contexto enunciativo que vivenciarão futuramente; trata-se de uma forma de inseri-los no contexto sócio-profissional em que desejam atuar.

\section{Algumas considerações sobre a sequência narrativa}

O pressuposto teórico do qual partimos é o de que os gêneros textuais em geral têm uma forma de organização composicional na qual, muitas vezes, predomina certa tipologia. O conhecimento dessa tipologia, assim como da organização composicional geral de um texto, inclui-se nos modelos textuais preestabelecidos destacados por Coirier, Gaonac'h e Passerault (1996) como um dos fatores determinantes para a produção textual, e constitui, por conseguinte, elemento fundamental da proficiência textual. Quando se trata do gênero de uma área profissional, o seu conhecimento apresenta-se de mais fundamental importante, tendo em vista que o descumprimento de determinadas estruturas esperadas para certo gênero pode gerar consequências profissionais desastrosas. $\mathrm{Na}$ área do Direito, em que os gêneros têm uma estrutura composicional mais fixa, mais institucionalizada (ADAM, 2011), essa questão se mostra de grande importância. Assim, apreender a estrutura dos gêneros que circulam na área jurídica torna-se crucial para os estudantes de Direito.

Considerando que os gêneros textuais trazem em sua composição sequências tipológicas, ou seja, unidades textuais dotadas de organização interna própria e da qual fazem parte outros elementos hierarquicamente organizados, conforme Adam (2011, p.205), consideramos igualmente importante explorar as sequências que compõem os gêneros a serem aprendidos pelos futuros profissionais. Conforme 
verificaremos a seguir, no caso do gênero Petição Inicial, destaca-se a sequência narrativa. Não podemos, entretanto, desconsiderar as sequências argumentativas, marca prototípica do discurso jurídico, especialmente o do contencioso, voltado para convencer juízes.

É importante também destacar que as sequências não podem ser consideradas isoladamente do conjunto do gênero em que se inserem; a esse respeito, recorremos novamente a Adam (2011), que esclarece que a sequência se encontra numa relação de dependência-independência com o conjunto mais amplo do qual faz parte (o texto). O fato é que ela desempenha uma função no conjunto do gênero, contribuindo para o cumprimento de sua função social; ela está a serviço do gênero em que se insere e é essa relação intrínseca que o estudante precisa perceber para avançar na sua escrita, pois dela depende o uso adequado dos elementos constitutivos do gênero no momento da produção textual.

Ainda com respeito à importância das sequências textuais e da própria estrutura geral do gênero, é importante lembrar que apreender ou planejar o conjunto de um texto exige um esforço intenso da memória e essa atividade deve estar adaptada às capacidades cognitivas, o que, segundo Vandendorpe (1992), justifica uma atenção à estrutura do texto. $\mathrm{O}$ fato de prender-se a um plano organizador, como o de uma sequência tipológica, permite ao produtor articular os diversos elementos e hierarquizá-los, podendo garantir uma produção mais eficaz com menor esforço. A esse respeito Coirier, Gaonac'h e Passerault (1996) observam que os esquemas textuais definem os conhecimentos a respeito da forma e da organização dos textos, pois conforme observam Van Dijk e Kintsch (1983), constituem estruturas gerais de conhecimentos que resumem as convenções e os princípios observados por uma dada cultura na construção de tipos específicos de textos.

Todos os falantes de uma língua conseguem narrar e compreender histórias, acontecimentos, experiências pessoais; com efeito, várias pesquisas apontam para a existência de um esquema narrativo comum que preside à produção de textos narrativos no seio de uma mesma comunidade. Trata-se de um esquema interiorizado, convencional, caracterizado também pela natureza linguística de sua composição, isto é, aspectos lexicais, sintáticos, tempos verbais, relações lógicas.

Desse ponto de vista, as sequências textuais são compreendidas não apenas como no nível da textualidade, mas também como elementos de natureza cognitiva, culturalmente organizados na memória, conforme os conhecimentos do produtor e seu contato com gêneros variados, constituídos de sequências diversas. Com respeito à produção, podemos afirmar que o domínio das categorias constitutivas das sequências textuais pode intervir no esforço do produtor, uma vez que elas the oferecem um plano organizador que inclui os elementos constitutivos da fatia 
do texto que deve compor, ou até mesmo do texto todo, auxiliando na concepção de uma representação do texto a ser produzido de acordo com seus objetivos e contribuindo para as escolhas que o produtor deverá operar no desenvolvimento da escrita. De acordo com Adam (2011, p.226), a sequência narrativa apresenta os seguintes elementos: Situação Inicial, Nó, Re-ação ou Avaliação, Desenlace (Resolução), Situação Final e pode ser assim esquematizada:

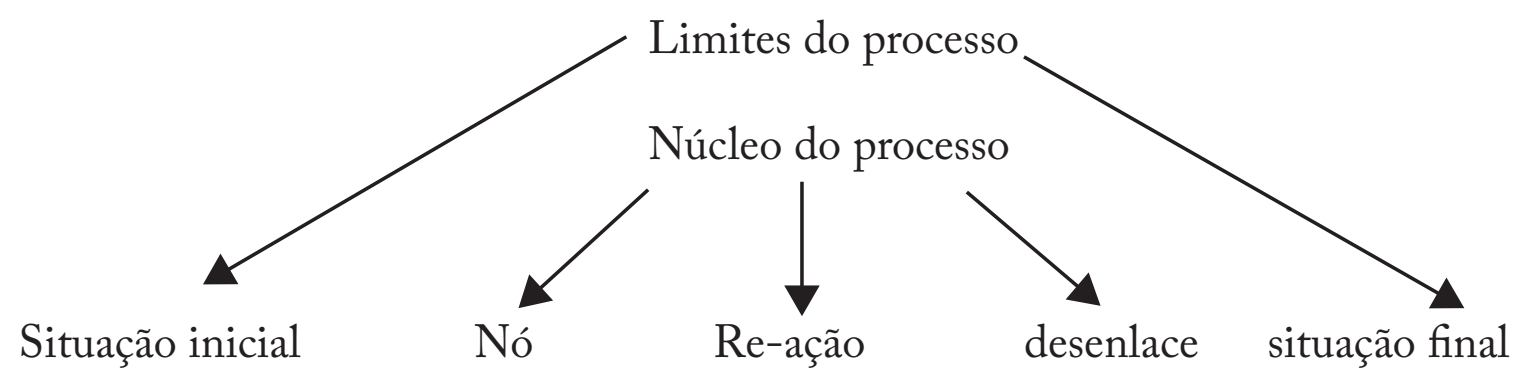

(esquema da sequência narrativa - ADAM, 2011, p.226)

Tratando também da construção de narrativa, François, Hudelot e SabeauJouanet (1984) destacam ainda três elementos como essenciais na sua constituição: personagens, tempo e relação entre os fatos narrados. $\mathrm{O}$ postulado dos autores justifica-se, pois conforme observam Sparano et al (2012, p.50) "a narrativa reúne conceitos como intenções, objetivos, ação, causa, consequências, intrigas, resolução de problemas; tudo isso inserido numa sequência temporal em que os fatos são apresentados como relacionados entre si”.

Adam (2001 [1997]), citando Bremond, propõe o apelo a seis constituintes que devem estar reunidos para que se possa considerar um texto ou uma sequência como narrativa. São eles: sucessão de eventos; unidade temática; transformação dos predicados; processo; causalidade narrativa de um conflito; e avaliação final. Esses constituintes também estão presentes nas considerações de François, Hudelot e Sabeau-Jouanet (1984).

Com relação à importância relativa dos elementos da narrativa, van Dijk (1992) parece priorizar a ação como elemento chave que conduz à resolução; François, Hudelot e Sabeau-Jouanet (1984), por sua vez, dão maior destaque à temporalidade; Adam, embora afirme que os seis componentes são fundamentais, parece dar maior destaque ao encadeamento dos fatos narrados, a temporalidade assumindo um papel de suporte a esse encadeamento, marcado, sobretudo, pelas relações causais.

Concordamos que as relações causais marcam o encadeamento de ações dentro da narrativa, como postula Adam; que a narrativa é marcada por ações, 
como ensina van Dijk; e que essas ações se sucedem no tempo, como preconizam François, Hudelot e Sabeau-Jouanet. Entretanto, esses autores encaram a narrativa de um ponto de vista geral, ou seja, apresentam os elementos que compõem um texto narrativo, ou os que devem estar presentes numa narração.

Do ponto de vista da importância da narrativa para o texto de jurídico no contencioso, ou seja, em relação ao que deve destacar o advogado no sentido de conduzir seu cliente à vitória na disputa jurídica, acreditamos ser, em primeiro lugar, o conflito, ou, como explicam Coirier, Gaonac'h e Passerault (1996), um acontecimento negativo que desencadeia uma complicação para determinado personagem ou para a história como um todo. Algumas considerações em torno do Processo Civil e da função do gênero Petição Inicial nos permitirão justificar a importância dada ao conflito na construção da sequência narrativa jurídica.

\section{A Petição Inicial: gênero marcado pelo conflito}

As sociedades se organizam objetivando a paz na convivência entre os cidadãos; assim, no convívio social, normalmente, os indivíduos vivem pacificamente, gozando de seus bens e exercendo seus direitos. Pode acontecer, no entanto, de um cidadão ter o seu interesse ameaçado por alguém, ou mesmo violado; estabelece-se aí um conflito de interesses, motivando nos sujeitos o desejo de subordinar o interesse do outro ao seu. Essa motivação dá origem ao que, em Direito, se chama uma "pretensão" (Santos, 1977). O Estado não permite ao particular fazer justiça por suas próprias mãos, mas lhe confere o direito de convocar o Estado para fazer atuar a vontade da lei visando a atender essa pretensão. Esse é o direito de ação.

A ação constitui, assim, conforme ensina Greco Filho (1995), o direito que têm os indivíduos de pedir ao Estado a prestação de sua atividade jurisdicional num caso concreto. Trata-se, entretanto de um direito abstrato, porque ele pode ser exercido tanto por quem tenha razão quanto por quem não a tenha. Cabe ao juiz apurar quem tem razão e determiná-la na sentença. Assim sendo, cada uma das partes envolvidas no processo tem o interesse de expor os fatos de maneira a convencer o juiz de que a razão lhe pertence e de que detém o direito de ter a sentença declarada a seu favor.

É importante esclarecer também que o Estado exige que os indivíduos sejam representados por advogados devidamente habilitados. O advogado é que assume a voz do cliente, falando em nome dele. Daí a importância de que esse profissional saiba expor o conflito por que passa seu cliente de forma adequada à conduzir o juiz a perceber as razões do indivíduo que pede a intervenção jurisdicional no cumprimento de sua função social. Santos (1977) ensina que o objetivo do Processo 
é solucionar conflitos de interesse. De fato, o Estado, por meio de sua prestação jurisdicional porá um fim ao conflito, buscando a paz jurídica. Entretanto, não podemos desconsiderar que na origem de um processo está um conflito que o motivou. O processo nasce de um conflito e é o conflito que vai marcar a relação entre as partes no desenrolar do processo; inclusive, há princípios legais que regem a relação entre as partes e um deles é o princípio do contraditório, segundo o qual os objetivos das duas partes devem ser contraditórios (SANTOS, 1977).

O Processo Civil funciona por provocação do interesse de uma das partes; isso quer dizer que a parte precisa agir, procurar um advogado, e por meio dele, propor o processo, fazendo valer seu direito de "ação", a fim de obter a proteção de seus direitos individuais. Só assim ocorre a "ação". O Processo se instaura com a "inicial”, por meio da qual o "autor" solicita a intervenção do judiciário para a aplicação da lei em relação a alguém (o "réu"), pedindo a sua "ação". A partir de então, haverá uma parte que afirma e uma parte que nega, e o juiz, a quem caberá decidir. Dessa dinâmica discursiva de afirmação e negação resulta uma "pendência" que perdurará até a sentença definitiva que porá fim à "ação", ou seja, trará a resolução final para o conflito.

Toda "ação", além das partes e do juiz, tem um objeto, que é o pedido do "autor"; ao pedido deve corresponder uma "causa de pedir", isto é, o pedido apoia-se em um fato gerador de conflito e deve ter respaldo na lei. O Código Civil brasileiro exige que o "autor" exponha, na " petição inicial", os fatos e os fundamentos jurídicos do pedido. Por isso, é de suma importância que o advogado da parte não apenas conheça o direito de seu cliente, mas também, e, sobretudo, saiba expor os fatos, mostrando claramente o conflito e a razão de seu cliente. Essa questão nos remete a Adam (2011), para quem "toda narrativa pode ser considerada como a exposição de "fatos"'. Daí a importância de se compreender essa estrutura sequencial de texto, em toda sua amplitude, sem descuidar de nenhum de seus elementos constitutivos.

É por meio de narração dos fatos que o juiz toma ciência dos fatos, e os avalia com base na lei; nesse sentido, mais do que a simples exposição dos acontecimentos, a narração dos fatos constitui estratégia argumentativa para convencer o juiz. A forma como esses fatos são apresentados pelo advogado no desenrolar do Processo pode conduzir a causa à vitória ou à derrota, daí a importância, para a atividade advocatícia, de se aprender a narrar de forma a convencer o juiz de que a versão apresentada é a que corresponde à realidade.

A Petição Inicial constitui um gênero cuja função social é instaurar um processo; é a primeira peça apresentada perante o juiz com o fim de pedir ao Estado a prestação de sua atividade jurisdicional num caso concreto; trata-se de um requerimento em que é formulado o pedido que dá início à "ação" judicial. O Código Civil brasileiro exige que o "autor" exponha, na petição inicial, o fato e os fundamentos jurídicos do pedido. 
Analogamente à estrutura narrativa defendida pelos estudiosos da linguagem, o conceito de processo civil apresenta uma estrutura que contempla os mesmos elementos que a narrativa: existe uma situação inicial, de harmonia entre as partes; esta harmonia é quebrada por uma das partes que ameaça ou viola o interesse da outra, instaurando um conflito; o processo instaurado pela petição inicial constitui a "ação" que, ao final, após a avaliação do juiz com postulação da sentença, conduzirá à "resolução". Assim sendo, a narrativa, na petição inicial, contempla apenas a situação inicial e o conflito, enfatizando-o. Podemos estabelecer um paralelo entre os acontecimentos relacionados do processo e a própria estruturação da sequência narrativa proposta por Adam (2011):

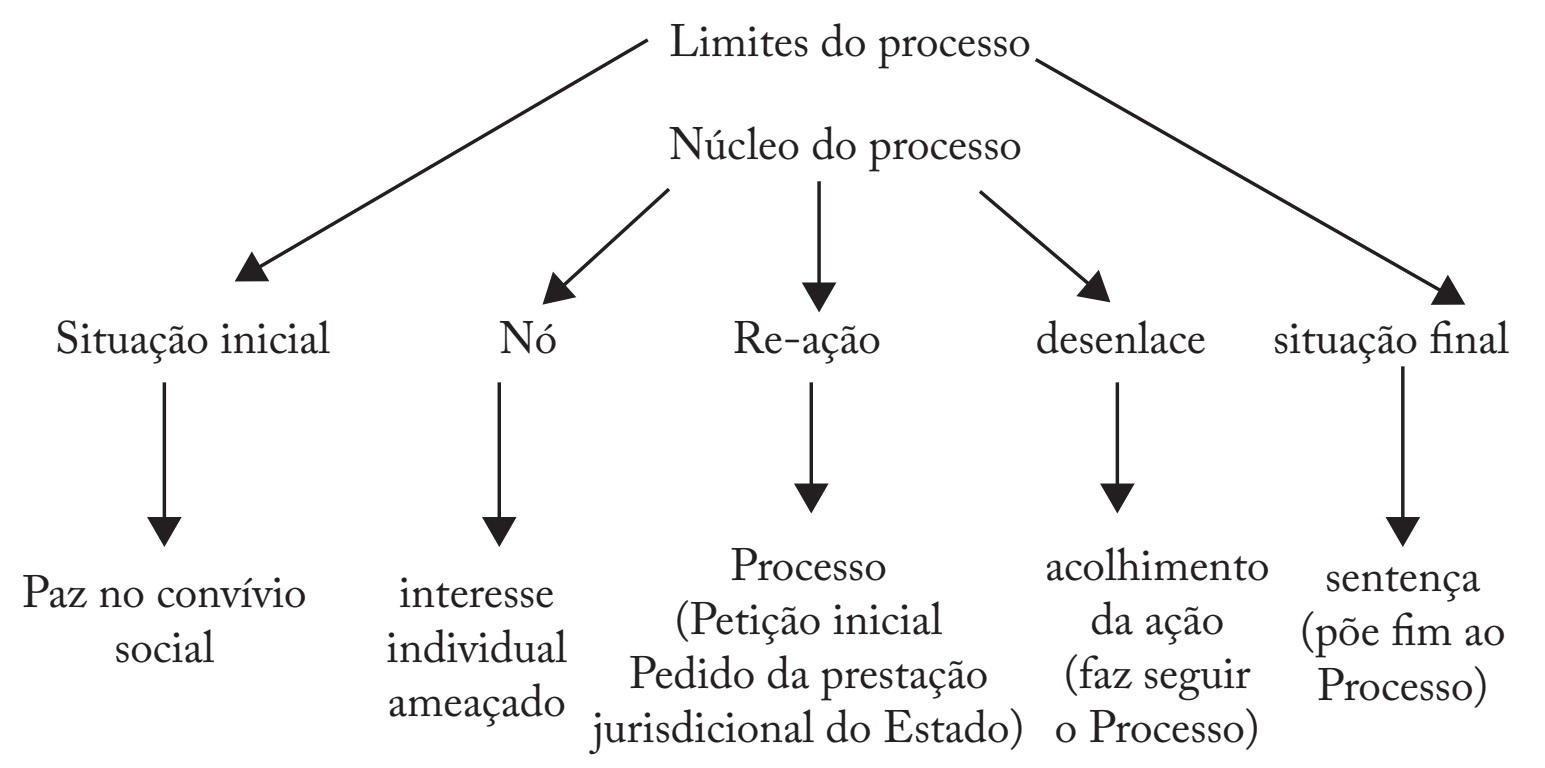

Por isso, dizemos que narrar, para o advogado, é mostrar um conflito. Em um processo, o advogado, na narração dos fatos, deve evidenciar uma complicação, ou seja, um conflito entre as partes para o qual houve, por parte de seu cliente, o "autor”, várias tentativas de solução, todas infrutíferas, não restando outra possibilidade senão invocar a "ação" do Estado para a sua "resolução". Nesse sentido, podemos dizer que o que caracteriza a narração jurídica, é a presença de um "conflito" que provoca uma "ação" e busca a sua "resolução".

Defendemos, por conseguinte, que o elemento chave para o texto narrativo, na área jurídica contenciosa, é a apreensão do estado de conflito, em torno do qual se desenrola a ação no eixo temporal. A noção de conflito está ligada ao conceito de intencionalidade, pois o conflito se estabelece a partir da oposição entre intenções dos personagens, ou partes, no caso de uma disputa jurídica. É importante que o juiz, principal leitor a quem se dirige o texto de uma ação judicial, perceba o 
conflito para que atribua sentido para as ações e, por meio do estabelecimento de relações entre elas, de diversas ordens, não apenas causais, construa a unidade do texto, no eixo da temporalidade. Cabe ao advogado apresentar uma narração que cumpra essa função, daí a importância de ensinar, no curso de Direito, as sequencias textuais narrativas como elementos chave do gênero Petição Inicial.

\section{Os elementos linguísticos da narração jurídica}

A disciplina Língua Portuguesa, quando acontece, normalmente, é ministrada no primeiro ano do curso de Direito, período em que os alunos ainda não possuem conhecimentos jurídicos que lhes permitam elaborar uma petição inicial inteira. Assim sendo, o trabalho centra-se no desenvolvimento de uma proficiência para escrever textos em cuja composição ocorram sequências de tipo narrativo, evidenciando a importância da narração como estratégia argumentativa na petição e do conflito como elemento desencadeador da ação judicial.

Conforme observa Bronckart (1999), os textos narrativos caracterizam-se pelo emprego predominante de verbos no pretérito perfeito ou no imperfeito; pela presença de organizadores temporais e de anáforas pronominais e nominais. $\mathrm{Na}$ área específica do Direito, apenas as anáforas pronominais são raras, uma vez que a linguagem técnica preconize a repetição dos nomes técnicos e rechaça o emprego de pronomes pelo risco de uma eventual ambiguidade referencial.

Normalmente, o cliente faz ao advogado um relato dos fatos de maneira desordenada e confusa. Cabe ao advogado selecionar elementos que se prestam à construção de seu texto. A atividade do advogado se inicia, assim, por um processo de escolhas, a fim de selecionar, dentre os fatos apresentados pelo cliente, aqueles que serão utilizados em sua narração. Em seguida, deve organizá-los na ordem lógica e cronológica a fim de se estabelecer a progressão. Nesse processo, ter em mente a organização sequencial da narrativa constitui um recurso estratégico: é importante expor uma situação inicial em que o indivíduo gozava de paz, exercendo seu direito pacificamente; somente depois de exposta a situação inicial é que cabe expor o conflito.

Ao construir a narração propriamente dita, a partir dos fatos enunciados pelo cliente, o advogado precisa mostrar com ênfase o conflito e apresentar o ponto de vista de seu cliente como sendo o único aceitável para a resolução do conflito. A narrativa deve, ainda, apresentar o cliente como a vítima dos fatos, evidenciando o valor negativo das ações da parte contrária. Assim sendo, além dos elementos linguísticos característicos das narrativas, é preciso considerar também a utilização de linguagem argumentativa da narração dos fatos. 
Defendemos que, para que os alunos sejam capazes de contemplar todos esses elementos na produção do gênero Petição Inicial, é importante que realizem, anteriormente ao trabalho de redação do gênero petição propriamente dito, atividades que considerem os meios linguísticos específicos de contemplá-los. Assim sendo, além do trabalho de exploração e análise de sequências narrativas em diferentes textos, literários e não literários, focalizando especialmente o reconhecimento do conflito, desenvolvemos um trabalho sistemático em torno das peculiaridades da linguagem jurídica; dos elementos linguísticos de uma sequência narrativa; de estratégias linguísticas de argumentação.

Depois de construir os conhecimentos prévios necessários à elaboração de sequências narrativas, é possível apresentar o conceito do gênero petição inicial, destacando sua função social, sua importância no Processo como um todo, sua estrutura composicional e a peculiaridades linguístico estilísticas. Vale destacar que a função do gênero permite justificar a sua estrutura composicional, que passa a fazer sentido para os estudantes. Eles podem assim compreender que a estrutura composicional do gênero não é apensa uma coerção legal ou uma imposição da área de atuação; ela se justifica para o fim ao qual está destinado o gênero.

Nessa fase do trabalho, os alunos já devem possuir os conhecimentos linguísticos e textuais para produzir a narração dos fatos de uma petição. Podemos então, como uma primeira atividade que os conduza a refletir com base nos conhecimento adquiridos, apresentar um texto contendo uma narrativa desordenada e recheada de fatos não pertinentes, ou não relevantes e solicitar que selecionem os fatos relevantes que deverão constar na narração, organizem-nos cronologicamente e, por último, produzam a narração dos fatos, utilizando linguagem adequada à peça jurídica; linguagem argumentativa; elementos de subjetividade e modalização; elementos de sequenciação e conexão; marcadores temporais e argumentativos.

\section{Considerações finais}

Neste texto focalizamos um gênero da atividade jurídica, a Petição Inicial, destacando sua função e sua estrutura, da qual as sequencias textuais narrativas constituem elemento fundamental. Apresentamos algumas diretrizes de como esse gênero pode ser trabalhado visando à proficiência escritora de estudantes de Direito, compreendendo que a proficiência em escrita não constitui uma habilidade geral, mas está circunscrita a determinados domínios a atividade humana, visto que não é possível escreve bem todo tipo de texto. No gênero Petição Inicial, especificamente na narração dos fatos, o advogado do "autor" faz um relato dos fatos que levaram seu cliente a propor a ação; tal relato deve atestar que o advogado em 
questão é dotado de "habilidade de comunicar-se com os outros e de articular seus pensamentos pela escrita" (MOLITOR-LÜBBERT, 2010, p.132), sendo o seu texto eficiente para o fim social a que se destina: conseguir a prestação jurisdicional do Estado em favor do cliente. O advogado mostrará assim ser "competente e eficiente no que faz" (HOUAISS e VILLAR, 2001, p.2306), isto é, ele será considerado proficiente na produção do gênero Petição Inicial.

O texto que desenvolvemos centra-se na escrita voltada para a formação de profissionais do Direito, entretanto, acreditamos que as breves reflexões apresentadas podem estender-se a outras áreas de formação profissional. Nossa preocupação foi destacar a importância da apropriação dos gêneros profissionais na formação universitária no Brasil, voltada para a inserção dos egressos na atividade profissional.

Defendemos que e efetiva inserção dos jovens no mundo profissional depende em grande da parte da compreensão que eles possam ter dos contextos em que se inserem suas ações, e essa compreensão passa necessariamente pela proficiência para escrever textos adequados à sua atuação. Para tanto, importa perceber o objetivos para os quais se desenvolvem as ações profissionais nas quais atuarão, sensibilizar-se para a necessidade de apropriação dos gêneros específicos na esfera profissional em que pretendem atuar, em sua amplitude, desde a estrutura composicional até as implicações linguísticas próprias ao gênero, mas sobretudo, compreender o contexto social em que se desenvolve a atividade profissional para qual se preparam para que sejam capazes de situar-se enunciativamente frente aos desafios profissionais a serem enfrentam, assumindo postura engajada com os objetivos a que se propõem no desempenho de vida como profissionais e como cidadãos.

\section{Referências}

ADAM, Jean-Michel. Les textes : types e prototypes, récit, description, argumentation, explication, et dialogue. Paris: Nathan, 2001 [1997].

. A Linguística Textual: introdução à análise textual dos discursos. Trad. Maria das Graças Soares Rodrigues, João Gomes da Silva Neto, Luis Passeggi, Eulália Vera Lúcia Fraga Leurquin. São Paulo: Cortez, 2011.

BRONCKART, Jean-Paul. Atividade de linguagem, textos e discursos por um interacionismo sócio-discursivo. São Paulo: EDUC, 1999. 


\section{Linha D'Água (Online), São Paulo, v. 28, n. 2, p. 122-136, dez 2015}

CABRAL, Ana Lúcia Tinoco. O conceito de plano de texto: contribuições para o processo de planejamento da produção escrita. IN: Revista Linha D'Água. Número 26 - 2 segundo semestre de 2013. Programa de Pós-graduação em Filologia e em Língua Portuguesa - Faculdade de Filosofia, Letras e Ciências Humanas, - Universidade de São Paulo. p.241-259. disponível em http://www.revistas.usp.br/linhadagua/index

CHUY, Maria. e RONDELLI, Fabienne. Traitement des contraintes linguistiques et cognitives dans la construcition de la cohérence textuelle. IN: Tratitement des contraintes de la production d'écrits: aspects linguistiques et psychologiques. Langages, n.177, mars 2010. Paris: Larousse, 2010, p.83-111.

COIRIER, Pierre; GAONAC'H, Daniel \& PASSERAULT, Jean-Michel. Psycholinguistique textuelle - une approche cognitive de la compréhension et de la production des texts. Paris: Armand Colin, 1996.

FAYOL, Michel.; FOULIN, Jean-Noël, MAGGIO, Séverine; LÉTÉ, Bernard. Towards a Dynamic Approach of How Children and Adults Manage Text Production.IN: GRIGORENKO, E.L.; MAMBRINO, E.; PREISS, D. D. (Eds.) Writing a mosaico of new perspectives. New York, London: Psychology Press/Taylor \& Francis Group, 2012, p.141-158.

FRANÇOIS, Frédéric; HUDELOT, Christian. e SABEAU-JOUANET, Emilie. Conduites linguistiques chez le jeune enfant. Paris: PUF, 1984.

GAONAC'H, Daniel. \& FAYOL, Michel. (coord.) Aider les élèves à comprendre du texte au multmédia. Paris: Hachette, 2003.

GRECO FILHO, Vicente. Direito Processual Civil Brasileiro 1º volume. São Paulo: Saraiva, 1995.

HAYES, John \& FLOWER, Linda. Identifing the Organization of Writing Processes. IN: CREGG, L. \& STEINBERG, E.R. (eds.). Congnitive Processes in Writing. Hillsdale: Laerence Erlbaum Ass. 1980, p.3-30.

HOUAISS, Antonio e VILLAR, Mauro Salles. Dicionário Houaiss da Lingua Portuguesa. Rio de Janeiro: Objetiva, 2001.

KELLOGG, Ronald e Whiteford, Alison. The Development of Writing Expertise. IN: GRIGORENKO, E.L.; MAMBRINO, E.; PREISS, D. D. (Eds.) Writing a mosaico f new perpectives. New York, London: Psychology Press/Taylor \& Francis Group, 2012, p. 109-124. 
Linha D'Água (Online), São Paulo, v. 28, n. 2, p. 122-136, dez 2015

MARQUESI, Sueli Cristina e CABRAL, Ana Lúcia Tinoco. Enunciação e Práticas Discursivas na Universidade: uma reflexão sobre dificuldades de escrita. IN: MICHELETTI, G (org.) Enunciação e Gêneros Discursivos. São Paulo: Cortez, 2008, p.148-172.

MOLITOR-LÜBBERT, Sylvie. A escrita como um processo mental e lingüístico. In: Weisser, H. P. e Koch, I. G. V. (org.) Linguística Textual: perspectivas alemãs. Rio de Janeiro, Nova Fronteira, 2009, p.121-165.

SANTOS, Moacyr Amaral dos. Primeiras linhas de direito processual civil: Adaptadas ao novo Código de Processo Civil. São Paulo: Saraiva, 1977.

SPARANO, Magalí ; GEBARA, Ana Elvira Luciano; CABRAL, Ana Lúcia Tinoco; CARVALHO, Helba; CURY, Beth. Gêneros Textuais construindo sentidos e planejando a escrita. São Paulo: Terracota, 2012.

VANDENDORPE, Christian.Apprendre à lire des fables. Une approche sémio-cognitive.Montreal: Le Préambule. 1989.

VAN DIJK, Teun. Cognição, discurso e interação. São Paulo: Contexto, 1992.

\& KINTSCH, Walter. Strategies of discourse comprehension. New York: Academic Press, 1983.

Recebido: 26/10/2015

Aprovado: 14/11/2015 